\title{
Analysis of Fall Accidents of Dizzy Patients in a Tertiary Hospital in South Korea (20II-20I5)
}

\author{
Sung Kyun Kim¹, Sung Ho Lee ${ }^{2}$, Seon Heui Lee ${ }^{3}$, Jae Jun Song ${ }^{2}$, \\ Mi Jung Gwak ${ }^{2}$, Hee Seon Lee ${ }^{2}$, and Gi Jung $\mathrm{Im}^{2}$ \\ ${ }^{I}$ Department of Otorhinolaryngology-Head and Neck Surgery, College of Medicine, Hallym University, Dongtan Sacred Heart Hospital, \\ Hwaseong; and ${ }^{2}$ Department of Otolaryngology-Head and Neck Surgery, Korea University College of Medicine, Seoul; and \\ ${ }^{3}$ Department of Nursing, College of Nursing, Gachun University, Seongnam, Korea
}

\section{어지럼 낙상 사고의 발생 유형 및 분석: 한국 3 차 의료기관에서의 5 개년간 분석}

김성균 $^{1} \cdot$ 이성호 ${ }^{2} \cdot$ 이선희 ${ }^{3} \cdot$ 송재준 $^{2} \cdot$ 곽미정 $^{2} \cdot$ 이희선 ${ }^{2} \cdot$ 임기정 $^{2}$

한림대학교 의과대학 동탄성심병원 이비인후과학교실, ${ }^{1}$ 고려대학교 의과대학 이비인후-두경부외과학교실, ${ }^{2}$ 가천대학교 간호대학 간호학과 ${ }^{3}$

\author{
Received December 8, 2016 \\ Revised January 19, 2017 \\ Accepted January 24, 2017 \\ Address for correspondence \\ Gi Jung Im, MD, PhD \\ Department of Otolaryngology- \\ Head and Neck Surgery, \\ Korea University \\ College of Medicine, \\ 73 Inchon-ro, Seongbuk-gu, \\ Seoul 02841, Korea \\ Tel $+82-2-920-6720$ \\ Fax $+82-2-925-5233$ \\ E-mail logopas@korea.ac.kr
}

Background and Objectives A fall refers to a sudden fall accident resulting in injury and hurt of the human body. In the hospital, fall accidents occur mainly in dizzy patients or elderly people, but can also occur even in young people who fail to adapt to the unfamiliar hospital environment. This study analyzed the incidence of fall accidents and its pattern in dizzy patients in a tertiary hospital in South Korea.

Subjects and Method This study was conducted using 477 fall accidents that occurred in a tertiary hospital in Korea from 2011 to 2015. Extensively investigated were related fall risk factors such as patient's sex, age, medical department, diagnosis, first witness, mental status, physical activity, patient risk factors, walking aids, medication use and treatment.

Results Dizziness induced falls consisted of $20.5 \%$ of the total fall accidents. Sedative medications were frequently used in patients of dizziness induced falls $(42.9 \%)$. Fall acidents were mainly detected by nurses $33 \%$. The frequente sites of fall were the bed rooms $(55 \%)$, the corridor $(15 \%)$ or the bath rooms $(8 \%)$. Types of physical damage were no damage $(47 \%)$, abrasion or bruising (20\%), laceration (10\%), bath rooms $(8 \%)$, fracture $(3 \%)$, and head trauma $(1 \%)$. In 532 treatments, observation was recommended for $68 \%$, sterilization $15.2 \%$, suture $4.7 \%$, cast $1 \%$, and surgery $1 \%$.

Conclusion The study finds that the fall risk screening test and Multifactorial Fall Prevention Program should be performed for all high-risk patients of fall. About $20 \%$ of falls were associated with otologic dizziness, and otolaryngology doctors should pay attention to the fall problem and the medication related to dizziness, which may potentially increase the risk of falls.

Korean J Otorhinolaryngol-Head Neck Surg 2017;60(6):271-8

\section{서 론}

낙상(falls)이란 “예기치 않게 바닥, 또는 낮은 위치로 자세

This is an Open Access article distributed under the terms of the Creative Commons Attribution Non-Commercial License (http://creativecommons.org/licenses/by-nc/4.0) which permits unrestricted non-commercial use, distribution, and reproduction in any medium, provided the original work is properly cited.
가 변경되는 사고”로 정의된다. 특히 노인 낙상의 발생이 지 속적으로 증가하고 있고 이는 심각한 손상으로 이어져 뇌출 혈, 골절 등 여러 합병증들이 발생하며 일부는 불구 또는 사 망에까지 이르는 경우도 있다. 낙상의 위험도가 증가하는 만 큼 낙상에 관련한 사회적 비용이 증가하게 된다. 낙상은 발생 시 가장 많은 합병증을 유발하는 손상 가운데 하나이며, 노인 
층의 건강, 독립적 생활, 삶의 질에 위협이 되며, 가족 구성원 들에게도 심각한 영향을 미친다.

노인 인구의 급격한 증가 추세 및 사회 노령화에 따라 낙상 은 보건의료의 중요한 문제가 되고 있다. ${ }^{1}$ 한국 통계에 의하면 매년 전체 노인의 $25.1 \%$ 가 낙상을 경험한다고 한다. ${ }^{2,3)}$ 특히 65 세 이상에서는 $1 / 3$ 의 인원이 낙상을 경험하게 되고, 72 세 이상에서는 2년마다 한 번 낙상을 경험할 수 있으며, 80세 이 상에서는 매년 낙상을 경험할 정도로 고령으로 갈수록 낙상 의 위험도가 증가한다. ${ }^{24)}$ 미국의 통계에 따르면 매년 54만 명 이 낙상 사고로 인하여 병원에 입원이 필요할 정도의 손상을 받으며 이 중 30 만 명은 후유증 및 불구에 이르고, 2 만 5 천 명 정도는 생명에 위협을 끼치는 치명적인 낙상에 관련된 손상을 당하게 된다. ${ }^{5)}$

낙상과 이로 인한 골절 및 상해는 노인에서 생존율과 기능 에 좋지 않은 영향을 미치고 노인의 의료비를 상승시키는 원 인이 된다. 전체 낙상 노인의 $72.4 \%$ 는 병원치료, $47.4 \%$ 는 낙 상 후유증을 경험하여, 이에 따른 노인 낙상으로 인한 의료 비 지출이 미국의 경우에는 2000년에 약 20조에서 2005년에 약 26조로 증가하였으며 2013년에는 약 34조 원에 이르게 되 었다. 미국의 경우 노인 낙상으로 인한 입원이 70 만 명에 달 하여 개인당 평균 진료비가 약 35000 달러에 이른다고 한다. ${ }^{6}$

최근 의료기관평가에서 환자 안전보장의 하나로 낙상 위험 환자의 관리가 강조되고 있다." 하지만 병원 경영진 및 간호부 의 일로만 치부되어 각 연관된 진료과에서의 관심이 현격히 낮은 것이 한국의 현실이다. ${ }^{8}$ 낙상은 신체적 요인 중 체력, 뇌 능력, 시력 및 청력보다는 걷기 능력(평형감각)과 밀접한 관련 이 있다고 보고되었다." 즉, 노화에 의한 평형 기능 감퇴뿐만 아니라 어지럼을 일으키는 여러 원인 질환들도 낙상을 증가 시킬 수 있다. 따라서 실제로 어지럼을 호소하는 환자의 치료 에 관련된 이비인후과 의사들이 낙상에 관심을 갖고 주의를 기울여야 할 이유가 된다.

어지럼을 주소로 이비인후과에 내원하는 환자들은 꾸준하 게 늘어가고 있으며 그중 65세 이상의 노인이 차지하는 비율 은 증가하고 있다. ${ }^{10)}$ 어지럼 환자 진료의 대부분은 질환의 진 단 및 치료에 집중되어 있어, 어지럼으로 인한 낙상 위험을 예 방하는 것 또는 평가 및 예방을 위한 구체적인 도구 및 중재 방법의 개발과 시행은 요원한 상태이다. 전정기능저하 및 장애 를 가진 노인환자의 약 60 80\%에서 낙상 경험이 있다. ${ }^{11)}$ 특 히 정상인에 비해 낙상의 위험이 12 배 정도 높은 것으로 나타 난 만큼 어지럼 환자의 진료를 담당하는 이비인후과 의사들 의 관심이 높아져야 할 필요가 있다. ${ }^{12)}$

본 연구는 한국의 한 3차 대학병원에서 2011 2015년까지 발생한 낙상의 현황에 대하여 분석하였으며, 연간 낙상 환자
보고 비율을 분석하여 제시하였다. 낙상 위험환자 관리지침 에 의하여 관리된 입원 환자 중 실제로 낙상이 발생한 경우 를 대상으로 삼았으며, 낙상 당시 작성된 낙상보고서를 근거 로 최초 목격자, 낙상 시 환자의 의식상태, 활동성, 위험요인, 낙상 유형, 낙상 장소, 환자의 신체적 손상, 낙상 손상에 대한 진단 및 치료 등에 대하여 분석하였다. 특히 어지럼에 의하여 낙상이 일어난 환자군과 어지럼 이외의 원인으로 낙상이 일 어난 환자군을 비교 분석하였다.

\section{대상 및 방법}

\section{대상 및 분석}

2011 2015년까지의 낙상이 발생되어 보고된 건은 전체 477 건이었다. 낙상 환자들의 평균 연령은 $66.3 \pm 18$ 세였으며, 남 자는 253명(53\%), 여자는 224명(47\%)이었다. 최초 목격자, 낙 상 시 환자의 의식상태, 활동성, 위험요인, 투약 유무, 낙상 유 형, 낙상 장소, 환자의 신체적 손상, 낙상 손상에 대한 진단 및 치료에 대하여 현황을 분석하였다. 본 연구는 고려대학교 안 암병원의 기관윤리심사위원회의 승인(IRB No. ED15350)을 받아 진행되었다.

\section{낙상 위험관리지침}

본 연구에서의 3차 병원은 의료기관인증제도인 Joint Commission International에서 규정한 병원 안전 수칙에 따라 낙 상 위험관리지침을 운영하여 병원 내 낙상을 관리하고 있다. 본 규정의 목적은 주기적인 낙상 위험평가를 통하여 낙상의 위험에 있는 환자에 대한 예방 활동을 통하여 낙상으로 인 한 안전사고를 예방 및 최소화시키는 것에 있다.

기본적으로 낙상 고위험 불변 요인에 해당하는 환자는 낙 상 고위험군으로 간주하는데, 환자 상태가 흥분, 현기증, 체위 성 저혈압, 수면, 배뇨장애, 시력/청력 장애에 해당하는 경우, 투약 관련 위험요인이 있는 경우(항우울제, 항불안제, 항정신 치료제, 마약, 수면제, 최면 진정제, 항경련제, 항고혈압제, 이 뇨제), 65 세 이상의 고령인 경우는 고위험군으로 분류한다.

성인 및 14세 이상 소아 입원 환자에 있어서 병원 입원 환자 낙상 평가도구는 Morse Fall Scale을 이용한다(Fig. 1). ${ }^{13,14)}$ 이 는 지난 3 개월간의 낙상 경험, 주 진단 외에 이차적 질환 여부, 보행보조기구, 정맥수액요법, 걸음걸이, 의식상태 등 6 가지 항목에 대하여 평가를 시행하여 0 125점으로 점수 평가한다. ${ }^{13)}$ 평가항목 총점이 51점 이상인 경우 낙상 고위험군으로 분류 한다. ${ }^{14)}$ 


\section{낙상보고서}

병원 입원 환자의 낙상 발생 시 담당 간호사는 낙상보고서 를 작성하여 담당 의사 및 병원 질 관리 위원회로 통보한다 (최초보고자). 낙상보고서는 환자의 나이 및 성별 등의 인적 사항, 최초 목격자, 환자의 체중 및 신장, 의식상태, 활동 및 기능성, 휠체어나 보행보조기구의 사용, 환자위험요인, 투약 등에 관련된 환자관련사항을 포함한다. 또한, 낙상 유형, 낙상 장소, 침대 낙상 시 상황, 미끄러지거나 넘어진 경우의 상황이 포함된다. 환자위험요인은 어지럼, 흥분, 전신쇠약, 마비, 체위 성 저혈압, 시력장애, 보행장애, 수면장애, 해당 없음으로 분 류되어 있다. 이 중 어지럼에 의하여 낙상이 일어난 환자는 98 명(20.5\%)이다.
낙상 사고의 안전사고 등급에 대하여 5 단계로 분류한다. 낙상 환자 안전사고 등급은 level 0 4의 5단계로 나눈다. 세 분하면 level 0은 사건/사고가 일어날 뻔하였으나 우연한/시 의적절한 중재를 통해서 사고가 발생하지 않은 경우이고, level 1은 사건/사고가 발생하였으나 환자에게 해가 없는 경 우이고, level 2는 사건/사고의 발생으로 인한 치료 또는 중 재가 필요한 경우이고, level 3은 입원기간이 연장되거나 퇴 원 시 장애를 일으키는 사건/사고인 경우이며, level 4는 주요 기능의 영구적 손상 및 사망에 가까운 위험한 상황 또는 환 자가 사망한 경우를 지칭한다. 보고서에는 의료진에게 보고, 진단된 환자의 신체적 손상, 치료 내용에 대하여 기술하며 문 제 원인에 대한 담당자의 의견 및 개선방안이 포함되어 있다.

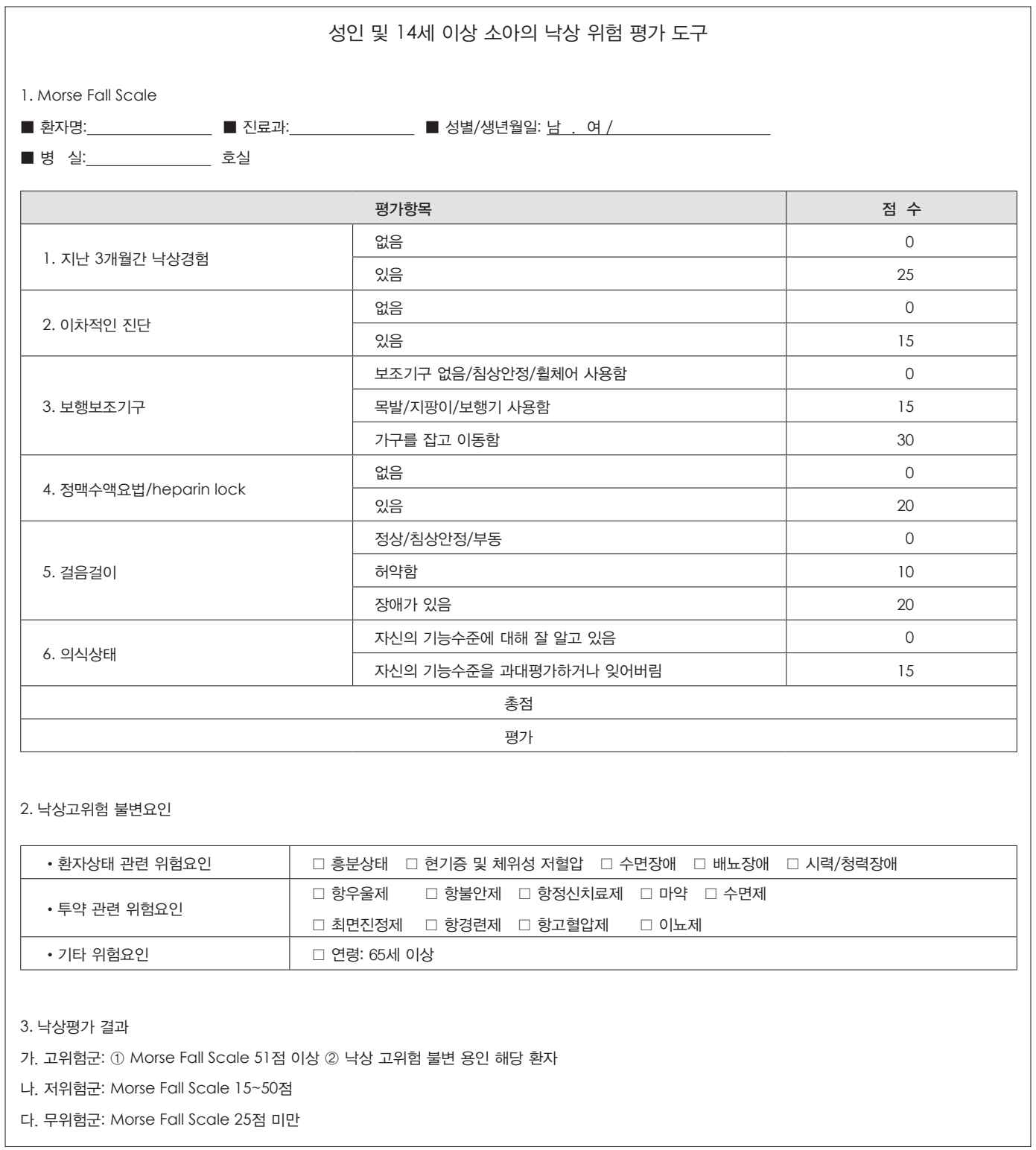

Fig. 1. Morse Fall Scale is a representative tool of evaluating the risk of fall in the adult patients of tertiary hospital. If the evaluation item score 51 points or more, thus the patient is classified as high-risk of fall. 


\section{결 과}

본 병원의 5 개년의 재원환자수는 1468772 명이며 보고된 낙상 환자수는 477 명이므로, 재원환자기준 연간 낙상 환자 보고 비율은 $0.032 \%$ 이다. 따라서 낙상 발생 환자수(1000재 원일당)는 0.32 명이 된다. 5 개년의 실입원 환자수는 215086 명이며 보고된 낙상 환자수는 477명이므로, 실입원 환자 기 준 연간 낙상 환자 보고 비율은 $0.22 \%$ 이다.

어지럼에 의하여 낙상이 일어난 환자는 98 명(20.5\%)이었 으며, 어지럼 이외의 원인으로 낙상이 일어난 경우가 379 명 (79.5\%)이었다(Table 1). 두 군의 평균 나이는 64.8 \pm 13.8 세와 $66.7 \pm 18.8$ 세로서 유사하였다. 안정제(벤조디아제핀 포함), 항 우울제, 항불안제, 항정신치료제, 마약, 수면제, 최면 진정제

Table 1. Comparison of characteristics between dizziness induced falls and non-dizzy patients induced falls. Dizziness induced falls consists of $20.5 \%$ from total fall accidents. Sedative medications were frequently used in the patients of dizziness induced falls. Distribution of departments was similar between two groups. There was a trend that dizziness induced falls was less severe than non-dizzy patients induced falls

\begin{tabular}{|c|c|c|}
\hline $\begin{array}{l}\text { Demographic } \\
\text { characteristics }\end{array}$ & $\begin{array}{l}\text { Dizziness induced } \\
\text { falls }\end{array}$ & Non-dizzy \\
\hline Number of patients (\%) & $98(20.5)$ & $379(79.5)$ \\
\hline Age & $64.8 \pm 13.8$ & $66.7 \pm 18.8$ \\
\hline Sedative medication (\%) & $42(42.9)^{\dagger}$ & $96(25.3)$ \\
\hline \multicolumn{3}{|l|}{ Department (\%) } \\
\hline $\mathrm{HO}$ & $23(23.5)$ & $114(30)$ \\
\hline NS & $12(12.2)$ & $33(8.7)$ \\
\hline PY & $10(10.2)$ & $26(6.9)$ \\
\hline GE & $9(9.2)$ & $26(6.9)$ \\
\hline NU & $5(5.1)$ & $27(7.1)$ \\
\hline ENT & $4(4.1)$ & $6(1.6)$ \\
\hline Etc. & $35(35.7)$ & $147(38.8)$ \\
\hline Total & $98(100)$ & $379(100)$ \\
\hline \multicolumn{3}{|l|}{ Fall accident class (\%) } \\
\hline 1 & $63(64.3)$ & $223(58.8)$ \\
\hline 2 & $34(34.7)$ & $156(41.2)$ \\
\hline 3 & $1(1)$ & 0 \\
\hline 4 & 0 & 0 \\
\hline \multicolumn{3}{|l|}{ Treatment (\%) } \\
\hline Observation & $85(77.2)^{*}$ & $277(65.6)$ \\
\hline Dressing & $9(8.2)$ & $72(17)$ \\
\hline Suture & $3(2.7)$ & $22(5.3)$ \\
\hline Cast & 0 & $3(0.7)$ \\
\hline Operation & $1(1)$ & $3(0.7)$ \\
\hline Etc. & $12(10.9)$ & $45(10.7)$ \\
\hline Total & $110(100)$ & $422(100)$ \\
\hline
\end{tabular}

$* p<0.05,{ }^{\dagger} p<0.01$. HO: hemato-oncology, NS: neurosurgery, PY: psychiatry, GE: gastro-enterology, NU: neurology, ENT: otolaryngology
등 졸리거나 어지럼을 유발할 수 있는 약을 투여한 경우가 어 지럼 낙상군에서 $42.9 \%$ 로서 어지럼 이외의 원인군(25.3\%)에 비하여 높게 나타났다 $(\dagger p=0.001$, Fisher's Exact Test). 환자 들의 진료과별 분포는 양 군에서 유사하였으며, 특히 암환자 들, 신경외과-정신과-신경과 관련 환자들이 낙상에 취약한 것으로 나타났다. 낙상 사고의 안전사고 등급은 어지럼 낙상 군에서 1 등급 $64.3 \%, 2$ 등급 $34.7 \%$ 로서 어지럼 이외의 원인 군(1등급 $58.8 \%, 2$ 등급 $41.2 \%)$ 에 비하여 심각한 낙상이 덜 일어나는 것으로 나타났다. 따라서 치료에 있어서도 단순 관 찰 이외의 추가적인 처치를 받은 환자들이 어지럼 낙상군에 서 $25.7 \%$ 로서 어지럼 이외의 원인군(34.4\%)에 비하여 낮게 나 타났다 $\left({ }^{*} p=0.022\right.$, Fisher's Exact Test)(Table 1).

낙상 발생 시 최초보고자는 간호사 33\%(157/477), 기타(타 환자 및 타 환자의 보호자) 31\%(46/477), 보호자 26\%(125/477), 간병인 10\%(149/477)로 조사되었다. 이는 입원 병실이 다 인실 로 이루어져 있는 한국의 특성상 같은 입원실에 있는 타 환자 및 보호자의 비율이 기타 $31 \%$ 로 분류된 것으로, 모든 환자와 보호자의 낙상 교육이 모든 환자들의 낙상 사고 대처에 도움 을 준다는 점을 시사한다(Fig. 2).

낙상 발생 시 환자의 의식상태는 명료한 상태 83\%(394/477), 졸음 10\%(46/477), 혼돈 7\%(36/477), 혼미 0.5\%(1/477)로 조 사되었다(Fig. 3). 이는 예상 외로 낙상이 의식이 명료한 상태 에서 부주의하거나 입원 환경에 부적응하여 생기는 경우가 많다는 것을 반증한다. 다만 환자의 활동성에 있어 독립적인 상태가 45\%(214/477), 부분적인 도움 필요 40\%(192/477), 항 상 도움이 필요한 상태 12\%(57/477), 의존적 2\%(11/477), 침대

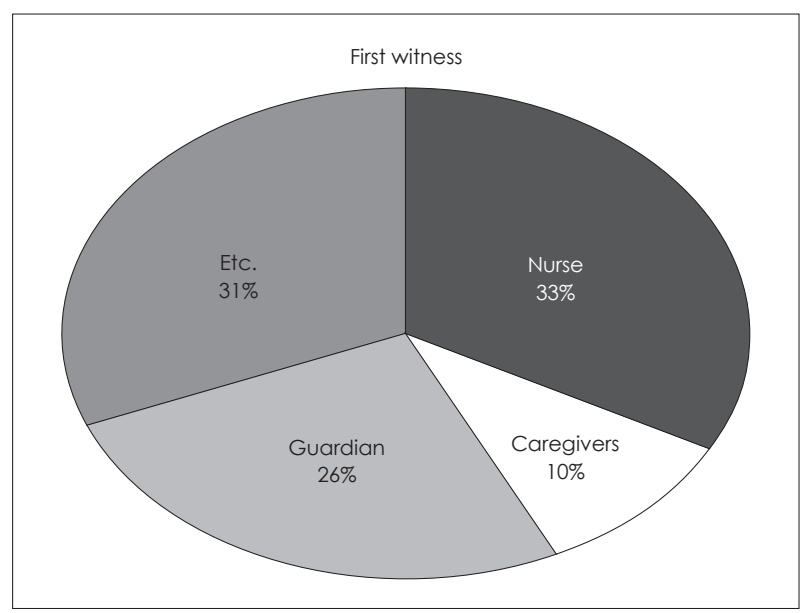

Fig. 2. Initial reporter of patient's falling accident consists of nurse $33 \%$, others people $31 \%$, guardian $26 \%$, and caregiver $10 \%$. In Korea, hospital room is a multi-bed room, therefore others not related to patients as initial reporter was so many $(31 \%)$. This result suggests that the education program of fall risk to whole members of hospital can be so important to prevent initial risk of falls in the hospital. 
생활 1\%(3/477)로 조사되었다(Fig. 4). 이는 도움이 필요한 상 태가 $55 \%$ 로서 자신이 스스로 움직이기에는 문제가 있다는 사 실을 간과하는 경우가 많다는 의미이다. 특히 휠체어 사용 $21 \%$ (100/477), 보행보조기구 사용 $12 \%(59 / 477)$ 의 결과를 보더라 도 $1 / 3$ 의 환자가 정상적인 보행이 어려운 환자들이 낙상을 경 험한다는 것을 알 수 있다. 환자의 위험요인에 대한 분석은 낙 상 사고 분석에 매우 중요하다(복수응답). 전신쇠약 29\%(203/

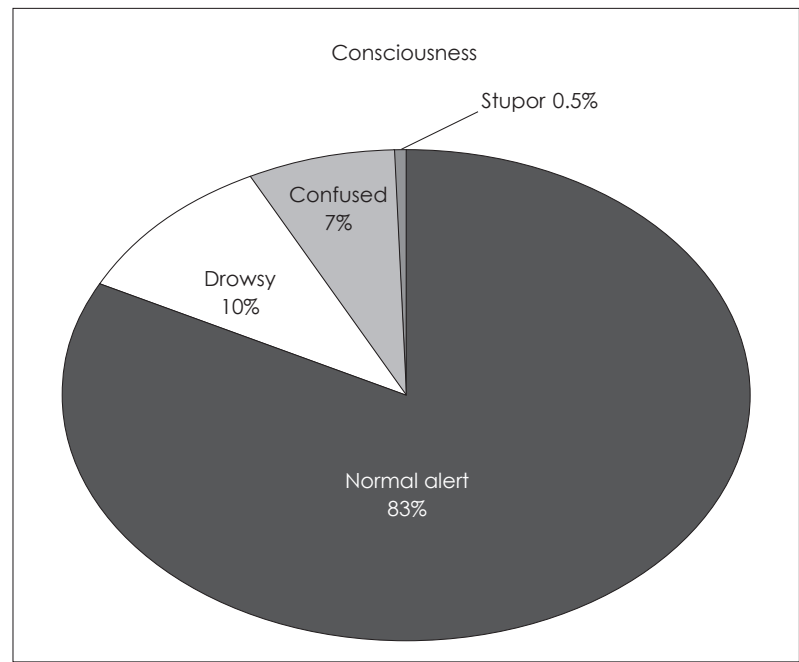

Fig. 3. In fall down, state of consciousness of the patients was examined as an alert normal consciousness $83 \%$, drowsiness $10 \%$, confusion $7 \%$ and stupor $0.5 \%$. This proves that patients can experience falling accident if careless or maladjustment in the hospital environment, even the patients have the state of clear consciousness.

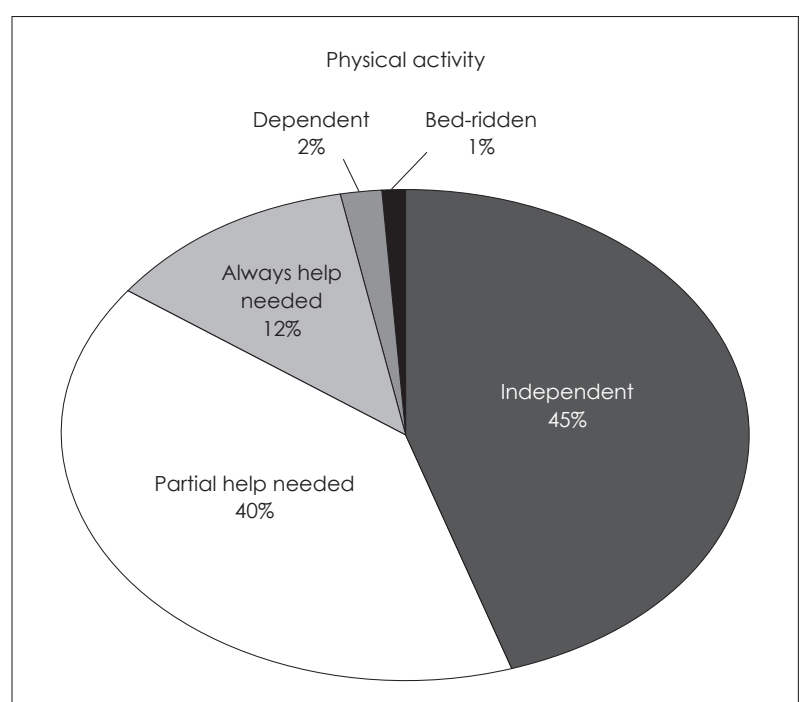

Fig. 4. The physical activity of the patients was examined as independent $45 \%$, need partial help $40 \%$, always help needed state $12 \%$, dependent $2 \%$, bed-ridden $1 \%$. This means that the patients may overlook the fact that his/her physical activity was problematic as $55 \%$. In particular, it can be seen that $21 \%$ of patients use wheelchairs and $12 \%$ of patients use walking aids, thus one third of patients will experience a fall because of difficulties of normal walking.
709), 보행장애 14\%(102/709), 어지럼 14\%(98/709), 수면장애 $10 \%(69 / 709), 1$ 년 이내의 낙상 과거력 $8 \%(54 / 709)$, 흥분 $3 \%$ (22/709)로 조사되었으며, 그 외에 체위성 저혈압, 평행 장애, 마비, 시력장애 등이 각각 $1 \%$ 정도로 조사되었다.

낙상 시 투약 유무의 경우 투약 76\%(356/469)였으나 아무 런 약도 투약 받지 않던 환자도 24\%(133/469)에 달하였다.

낙상 발생 상황의 경우 보행 시 38\%(181/477), 침대 34\% (162/477)로 조사되어 의료장비 $1 \%(7 / 477)$, 의자 3\%(13/477) 에 비교하여 현격하게 높았다(Fig. 5). 낙상 장소의 경우 병실 $55 \%(263 / 477)$, 복도 15\%(73/477), 화장실 8\%(40/477), 응급 실 3\%(13/477), 검사실 3\%(12/477), 샤워실 2\%(10/477), 중환 자실 1\%(4/477), 기타 13\%(62/477)로 조사되었다(Fig. 6). 이

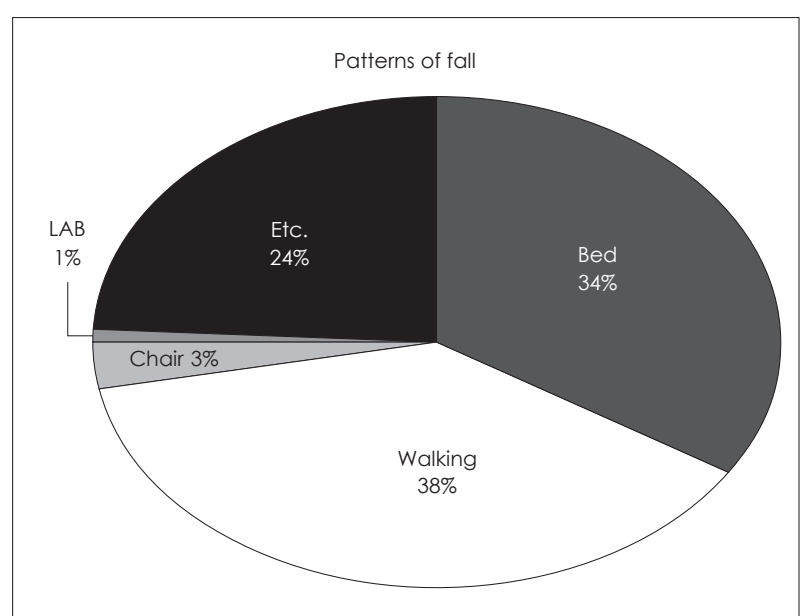

Fig. 5. The situation of falling accident was evaluated as In-thewalking $38 \%$ and beds $34 \%$, which shows dramatically higher percentage compared to medical equipment (LAB, laboratory) $1 \%$ and chair $3 \%$.

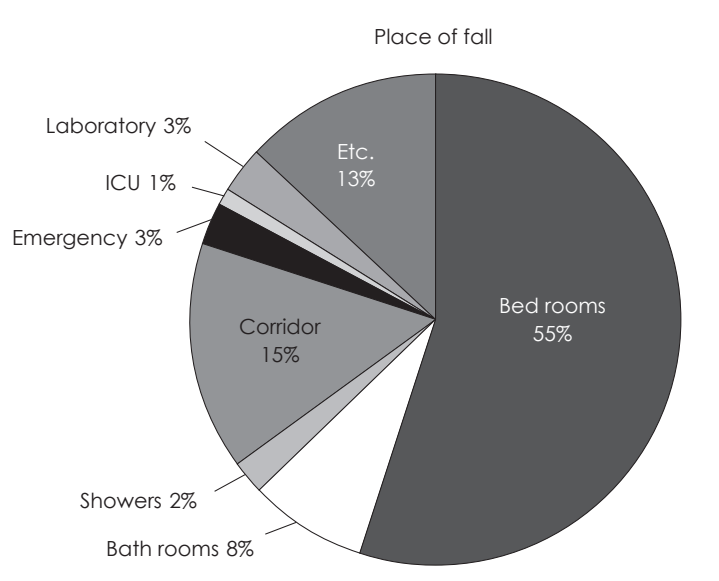

Fig. 6. Considering the place of falling accidents, hospital bed rooms were the most frequent place for fall down as 55\%, corridor $15 \%$, bath rooms (toilet) $8 \%$, emergency room $3 \%$, laboratory $3 \%$, showers $2 \%$, ICU $1 \%$, and others $13 \%$. This result shows that falling accidents usually occurred in the main living space of hospital $(78 \%)$, which indicates how important the education for fall risk. ICU: intensive care unit. 
는 환자의 주요 생활 공간인 병실-복도-화장실이 $78 \%$ 에 달 해 일상적인 낙상 주의 교육이 얼마나 중요한가를 나타낸다.

침대 낙상의 원인 분석 결과, 보조 난간이 없었던 경우 $12 \%$ (55/476), 침상주변 물건이 원인인 경우 3.6\%(17/476), 바퀴 고 정이 안되었던 경우 $0.4 \%$ (2/476) 등으로 조사되었다. 미끄러져 넘어진 경우의 원인 분석 결과상 주변 물건 원인 6.9\%(33/477), 신발 미적합 6.3\%(30/477), 물에 미끄러진 것 5.2\%(25/477) 등으로 조사되었다.

의료-간호진의 낙상 위험 예측 기록은 $92 \%$ 에서 작성되었 으며, 낙상 위험 예방 교육도 $97 \%$ 에서 이루어져서 높은 수준 의 예방 활동이 이루어지고 있음을 알 수 있다. 낙상은 모든 경우에서 의료진에게 즉각 보고되었으며 절반에서 추가적인

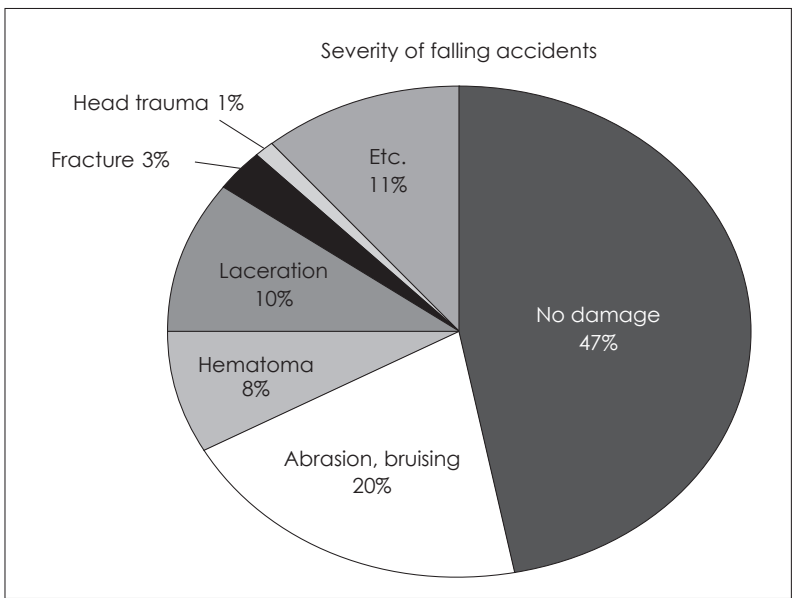

Fig. 7. The severity of falling accidents was examined as no damages $47 \%$, abrasion and bruising $20 \%$, laceration $10 \%$, hematoma $8 \%$, fracture $3 \%$, head trauma $1 \%$, and $11 \%$ were classified as others.

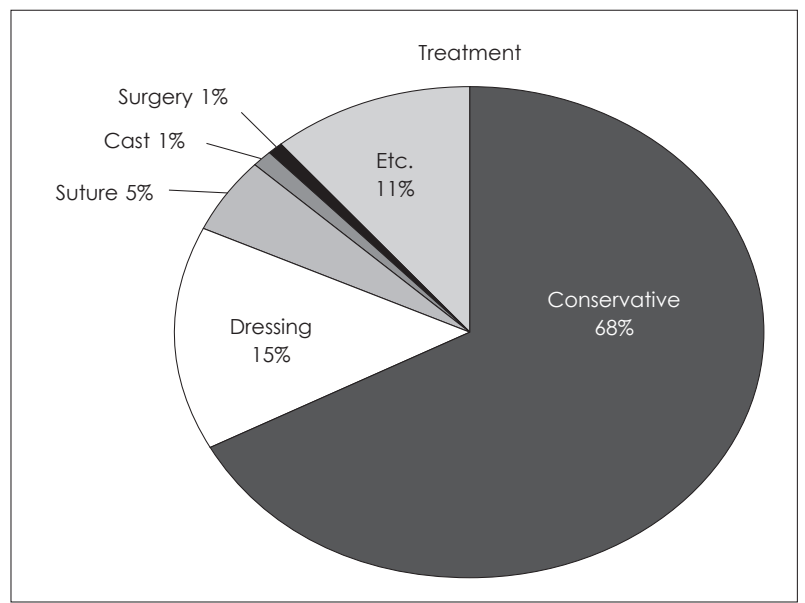

Fig. 8. The treatment information for falling accidents was gathering from a total of 532 cases as conservative treatment 362 cases $(68 \%)$, dressing 81 cases $(15.2 \%)$, suture 25 cases $(4.7 \%)$, cast for 3 cases, and need surgery for 4 cases. This results show that about $6 \%$ of the patients of falling would have received additional treatment such as suture, cast, and surgery.
검사를 시행 받았다. 추가적인 검사는 대개 엑스레이 영상검 사 $57 \%$, 전산화단층촬영 $33 \%$ 로 이루어졌다. 이러한 결과 환 자의 신체적 손상이 전혀 없는 경우 44\%(229/515), 약간이나마 손상이 있는 경우 43\%(221/515), 경제적 손실 12.6\%(62/515) 로 나타났다(복수응답).

안전사고 등급은 전체 469건 중 level 1은 286건(60\%), level 2는 190건(39.8\%), level 3은 1건(0.2\%), level 4는 단 한 건도 발생하지 않았다. 다행스럽게도 중대한 낙상은 극히 드물지 만 치료 또는 중재가 필요한 경우가 $40.9 \%$ 에 이른다는 점에 서 지속적인 낙상 예방 교육은 필요하리라 본다.

낙상으로 인한 신체적 손상으로는 전혀 없는 경우 47\%(239/ 509), 찰과상(abrasion) 및 멍(bruising) 20\%(104/509), 열상 (laceration) 10\%(51/509), 혈종(hematoma) 8\%(38/509), 골 절(fracture) $3 \%(15 / 509)$, 두부외상 $1 \%(7 / 509)$, 기타 $11 \%(55 / 509)$ 로 분류되었다(Fig. 7). 낙상 손상에 대한 치료 내용으로 총 532건 중 경과 관찰 362건(68\%), 소독 81건(15.2\%), 봉합(suture) 25건(4.7\%), 깁스(cast) 3건, 수술 4건 등으로 조사되었다(Fig. 8). 이는 6\%(32/532) 정도의 낙상 환자들이 봉합 이상의 추가 적인 처치를 받은 것으로 분석되었다(다중손상포함).

\section{고 찰}

본 연구에서는 어지럼에 의하여 낙상이 일어난 환자는 $20.5 \%$ 였으며, 어지럼 이외의 원인으로 낙상이 일어난 경우가 $79.5 \%$ 였 다. 어지럼 낙상군에서 안정제, 항우울제, 수면제 등 졸리거 나 어지럼을 유발할 수 있는 약을 투여한 경우가 더 높아 투약 하는 약물들을 잘 살펴 조정하여야 할 필요성이 있다. 어지 럼 낙상군에서 다행히 심각한 낙상이 덜 일어나는 것으로 나 타나고, 치료에 있어서도 단순 관찰 이외의 추가적인 처치를 받은 환자들이 $25.7 \%$ 로서 어지럼 이외의 원인군(34.4\%)에 비 하여 낮게 나타났다. 이는 어지럼 환자들은 움직임이 제한되 고 보행 능력은 어느 정도 유지되는 데 반하여, 흥분-전신쇠 약-마비-보행장애 등에 따른 낙상은 더욱 크게 넘어지고 큰 사고로 연결될 수 있다는 점을 시사한다.

본 연구에서 낙상 발생 시 최초보고자는 담당 간호사 및 보호자가 약 $70 \%$ 로 조속한 발견과 조치가 이루어진 것으로 보인다, 다만 낙상 시 보호자 또는 의료진이 옆에 없었던 경 우도 $52 \%$ 에 달하여 특히 환자 혼자 생활하는 경우에는 지 속적이고 특별한 관심이 필요하리라 생각된다. 병원의 타 직 원 및 타 환자-보호자가 발견하는 경우도 $31 \%$ 에 달하여 병원 의 모든 인원에게 낙상 교육이 필요하다는 것을 알 수 있다.

본 연구에서 낙상 발생 시 환자의 의식상태는 명료한 상태 $83 \%$, 환자의 활동성에 있어 도움이 필요한 상태가 $55 \%$ 로서 
이는 명료한 의식을 가지나 정상 보행이 어려운 도움이 필요한 상태에서 낙상을 경험하게 되므로, 환자가 자신의 능력을 맹 신하고 무리하게 행동하려다가 낙상을 경험하는 경우라 해석 할 수 있다.

본 연구에서의 입원 환자 낙상은 주로 병실(55\%)과 복도 (15\%)에서, 보행하는 경우(38\%) 및 침대에서 내려오는 동작 (34\%)에서 발생한다는 것을 알 수 있었다.

본 연구에서는 중대한 낙상은 극히 드물지만, 치료 또는 중 재가 필요한 경우가 $40.9 \%$ 에 이르고 $6 \%$ 정도의 낙상 환자들 이 봉합 이상의 추가적인 처치를 받은 것이라 주의를 요한다. 또한 낙상의 결과로 환자의 신체적 손상, 경제적 손실 등이 발 생하는 경우가 약 $55 \%$ 에 달하여 낙상 예방의 중요성을 일깨 운다.

낙상의 위험인자는 다양하여 낙상의 분류 및 중재 방법에 대하여 통합적인 접근이 필요하다. ${ }^{15)}$ 하지만 낙상 위험도 분 류 및 예방을 위한 중재 방법들은 환자의 기저 질환 및 복용 약물, 근력, 인지능력 등을 통합적으로 고려하여 계획하는 것 이 효과적이나 통상적이고 획일적인 기준만으로 이루어지고 있는 실정이다. ${ }^{16)}$ 낙상의 위험인자 분류는 보편적으로 육체적 (physical), 정신사회적(psychosocial), 환경적(environmental) 인자로 나눌 수 있다. 육체적 인자로는 하지 근력의 저하, 균 형감각 저하, 보행 실조, 어지럼, 관절염 등의 만성 근·골격계 질환, 시력저하 등이 있고, 정신사회적 인자로는 80세 이상의 고령, 낙상 과거력으로 인한 두려움, 일상생활능력 저하, 우 울증, 인지기능장애, 다양한 약제의 복용, 신경계 질환의 동 반 등을 들 수 있으며, 환경적 인자로는 가정 내에서의 침실, 계단, 욕실, 부엌, 거실 등에서의 환경적 장애물, 가족 구성원 의 수, 동거 유무들로 정리할 수 있다. ${ }^{17)}$ 이상의 위험인자는 내 인성 요인(intrinsic factors)과 외인성 요인(extrinsic factors)으 로 분류하기도 한다. ${ }^{18)}$

본 연구의 낙상 사례들에 대하여 보고 간호사들의 원인 분 석 및 개선안을 합하여 보면 실제로 행하여지는 낙상 예방 교 육의 지침이 된다.

병실 사고의 유형은 침대 난간을 올리지 않아 낙상하는 경 우가 많고, 고정되어 있지 않은 보호자의 침대를 밟고 내려오 다가 미끄러지는 경우가 많다. 또한 보호자의 도움없이 혼자 무리하게 움직이려는 경우가 많아서 침대의 바퀴는 항상 고 정하고, 침대 난간은 항상 올려 두어야 한다. 침대 높이는 가 능한 낮게 유지하는 것이 좋고, 침대에 오를 때는 보호자 및 간병인의 도움을 받아 천천히 오르도록 지도해야 한다. 또한, 침대에서 내려올 때 침대 난간을 내리고 천천히 내려오며, 침 대 난간 사이를 무리하게 내려오지 말아야 한다. 보호자 침대 는 미끄러질 수 있어 밟지 않으며, 신발을 잘 신고 내려와야
한다. 자주 사용하는 물건은 손이 닿을 수 있는 가까운 곳에 보관하고, 침대 아래로 떨어진 물건은 무리하여 주우려 하지 말고 도움을 요청하도록 한다. 환자의 관찰이 용이하도록 낮 에는 침상 커튼을 걷어 둔다.

복도 사고의 원인은 대개 자신의 보행 능력을 과신하고 무 리하게 혼자 걸어가다가 낙상하는 경우, 신발을 구겨 신거나 맞지 않는 신발 또는 슬리퍼를 신고 걷는 경우가 많다. 따라서 보행기, 휠체어, 지팡이 등을 잘 이용하도록 하고, 바짓단이 걸 리지 않도록 하고 발에 맞는 신발을 선택하며 수액줄/배액관 이 걸리지 않도록 주의해야 한다.

의자 사고의 원인은 주로 부적절한 휠체어의 사용이다. 특 히 휠체어를 잠금 장치로 고정하지 않고 타려고 하다가 휠체 어가 미끄러지면서 낙상하는 경우가 많다. 휠체어의 발판에 걸 려 넘어지거나 보호자의 관찰/도움이 없이 휠체어를 사용하다 가 넘어지는 경우도 있다. 따라서, 휠체어를 타고 내릴 때 잠금 장치를 항상 사용하고 발판을 잘 정리하도록 지도해야 한다.

화장실을 오고 가다가 낙상이 일어나는 경우도 많다. 다 인 실을 주로 사용하기 때문에 화장실 등에서 옷을 갈아입거나 혼자 동작을 하는 경우에는 낙상이 일어날 수 있다. 특히, 익 숙하지 않은 병원 환경에서 밤에 혼자 화장실을 오고 가는 것 은 위험하다. 야간에는 개인 조명을 사용하여 시야를 확보하 고 이동하도록 한다. 변기에서 용변을 보고 일어나는 중에 어 지럼을 느끼는 경우가 많고, 화장실 및 샤워실 바닥의 물에 미끄러지는 경우가 많다. 따라서, 취침 전에는 항상 화장실을 다녀 오도록 하고, 야간에 화장실로 이동할 때는 보호자의 도 움을 받는 것이 좋다. 배뇨장애가 있는 환자는 특히 수분 섭취 등을 조절하는 것이 좋다.

본 연구는 한국 소재의 한 3차 대학병원에서 일어난 실제 낙 상 현황에 대한 소중한 분석 자료가 되며, 이 자료는 낙상 환자 관리지침과 낙상 평가 및 낙상 예방 교육에 대하여 개선의 여 지를 시사한다고 볼 수 있다. 외래, 입원, 응급실, 수술실 등의 모든 환자에게는 낙상 위험도 선별검사가 시행되어야 하며 고위험군으로 분류된 환자들에게는 추가적인 다면적 낙상 평가가 필요하리라 여겨진다. 이러한 다면적 낙상 평가에는 약물 복용 과거력, 시력, 근력, 심혈관, 발 및 신발, 골다공증, 신체기능, 낙상에 대한 두려움, 인지기능, 배뇨장애, 환경 위험 성 등의 요소가 포함되어야 한다. 본 연구에서 밝혀진 다양한 요인과 대처법들이 이러한 다면적 낙상 평가 개발에 도움이 될 것이며, 실제적인 낙상 예방 교육의 지침이 되리라 여겨진다.

결론적으로 이비인후과적인 어지럼과 연관하여 전체 낙상 중 약 $20 \%$ 의 낙상 환자가 발생하는 것으로 본 연구에서 분석 된다. 어지럼과 연관될 수 있는 약제를 하나 이상 투약 받은 환자가 전체 낙상 환자 중 $76 \%$ 에 달하였다. 특히 다른 낙상 환 
자들과 달리, 어지럼으로 낙상한 환자들에게 진정작용이 있 는 약물이 더욱 많이 투약된 사실을 볼 때 이비인후과 의사 들이 낙상 예방을 위하여 어지럼 약물들을 잘 알고 조정하 여야 한다. 또한, 낙상에 대하여 관심을 가지고 사전 평가, 약 물 조절, 예방 교육, 전반적인 낙상 환자 관리지침 등에 대하여 알고 대처하여야 환자의 안전관리 및 의료 질 향상에 만전을 기할 수 있다.

\section{Acknowledgments}

This work was supported by the National Research Grant funded by the Korea Health Industry Development Institute (R1606511), and research fund (K1609821). These funding sources provide only financial support and play no specific scientific role in this study.

\section{REFERENCES}

1) Kannus P, Sievänen H, Palvanen M, Järvinen T, Parkkari J. Prevention of falls and consequent injuries in elderly people. Lancet. 2005;366 (9500):1885-93.

2) Bae J, Cho SI. [Effects of community-based comprehensive fall prevention program on muscle strength, postural balance and fall efficacy in elderly people]. J Korean Acad Nurs 2014;44(6):697-707.

3) Shin KR, Kang Y, Hwang EH, Jung D. The prevalence, characteristics and correlates of falls in Korean community-dwelling older adults. Int Nurs Rev 2009;56(3):387-92.

4) Riley R. Accidental falls and injuries among seniors. Health Rep 1992;4(4):341-54.

5) Tibbitts GM. Patients who fall: how to predict and prevent injuries. Geriatrics 1996;51(9):24-8, 31.

6) Stevens JA, Corso PS, Finkelstein EA, Miller TR. The costs of fatal and non-fatal falls among older adults. Inj Prev 2006;12(5):290-5.

7) Jung D, Shin S, Kim H. A fall prevention guideline for older adults living in long-term care facilities. Int Nurs Rev 2014;61(4):525-33.
8) Schwenk M, Lauenroth A, Stock C, Moreno RR, Oster P, McHugh G, et al. Definitions and methods of measuring and reporting on injurious falls in randomised controlled fall prevention trials: a systematic review. BMC Med Res Methodol 2012;12:50.

9) Gu MO, Jeon MY, Eun Y. [The development \& effect of a tailored fall prevention exercise for older adults]. Taehan Kanho Hakhoe Chi 2006;36(2):341-52.

10) Agrawal Y, Carey JP, Della Santina CC, Schubert MC, Minor LB. Disorders of balance and vestibular function in US adults: data from the National Health and Nutrition Examination Survey, 2001-2004. Arch Intern Med 2009;169(10):938-44.

11) Hansson EE, Månsson NO, Ringsberg KA, Håkansson A. Falls among dizzy patients in primary healthcare: an intervention study with control group. Int J Rehabil Res 2008;31(1):51-7.

12) Liston MB, Bamiou DE, Martin F, Hopper A, Koohi N, Luxon L, et al. Peripheral vestibular dysfunction is prevalent in older adults experiencing multiple non-syncopal falls versus age-matched nonfallers: a pilot study. Age Ageing 2014;43(1):38-43.

13) Kim KS, Kim JA, Choi YK, Kim YJ, Park MH, Kim HY, et al. A comparative study on the validity of fall risk assessment scales in Korean hospitals. Asian Nurs Res (Korean Soc Nurs Sci) 2011;5(1): 28-37.

14) Morse JM. Computerized evaluation of a scale to identify the fallprone patient. Can J Public Health 1986;77 Suppl 1:21-5.

15) Stevens JA, Phelan EA. Development of STEADI: a fall prevention resource for health care providers. Health Promot Pract 2013;14(5): 706-14.

16) Sohng KY, Moon JS, Song HH, Lee KS, Kim YS. Risk factors for falls among the community-dwelling elderly in Korea. Taehan Kanho Hakhoe Chi 2004;34(8):1483-90.

17) Choi EJ, Kim SA, Kim NR, Rhee JA, Yun YW, Shin MH. Risk factors for falls in older Korean adults: the 2011 Community Health Survey. J Korean Med Sci 2014;29(11):1482-7.

18) Rubenstein LZ. Falls in older people: epidemiology, risk factors and strategies for prevention. Age Ageing 2006;35 Suppl 2:ii37-41. 